\title{
Mapping groundwater dynamics using multiple sources of exhaustive high resolution data
}

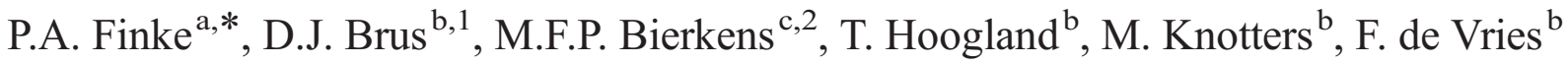 \\ ${ }^{a}$ Biometris, Wageningen University and Research Centre, P.O. Box 100, 6700 AA Wageningen, The Netherlands \\ ${ }^{\mathrm{b}}$ Alterra, Wageningen University and Research Centre, P.O. Box 47, 6700 AA Wageningen, The Netherlands \\ ${ }^{\mathrm{c}}$ Department of Physical Geography, University of Utrecht, P.O. Box 80115, 3508 TC, Utrecht, The Netherlands
}

Received 30 January 2003; received in revised form 3 October 2003; accepted 14 January 2004

Available online 4 March 2004

\begin{abstract}
Existing groundwater table (GWT) class maps, available at full coverage for the Netherlands at 1:50,000 scale, no longer satisfy user demands. Groundwater levels have changed due to strong human impact, so the maps are partially outdated. Furthermore, a more dynamic description of groundwater table dynamics representative for the current climate is needed. A mapping method to obtain a large set of parameters describing groundwater table dynamics was developed. The method uses time series analysis and well-timed phreatic head measurements to obtain a data set at point support. This point data set is correlated to groups of exhaustive high-resolution ancillary data by stratified multiple linear regression. Finally, simple kriging is applied to interpolate the residuals of the regression model. The method was applied in a 1,790,000 ha area and its performance was measured in 10,000 and 179,000 ha test areas. The relation between higher sampling density, mapping cost and map quality was explored. Validation results show that reasonable to good quality maps of various aspects of groundwater dynamics can be obtained by this method, at much lower cost than traditional survey-based mapping methods. The method includes the quantification of uncertainty at the actual sampling density and allows the a priori estimation of uncertainty at other sampling densities. Future research aims at identification of the effect of sources of error in ancillary data and how to diminish these.
\end{abstract}

(C) 2004 Elsevier B.V. All rights reserved.

Keywords: Water tables; Maps; Geostatistics; Temporal statistics; Accuracy

\section{Introduction}

Groundwater table (GWT) class maps are the only full-cover data source describing the seasonal fluctu-

* Corresponding author. Fax: +31-317-413554.

E-mail addresses: p.a.finke@plant.wag-ur.nl (P.A. Finke), d.j.brus@alterra.wag-ur.nl (D.J. Brus), m.bierkens@geog.uu.nl (M.F.P. Bierkens).

${ }^{1}$ Fax: +31-317-419000.

${ }^{2}$ Fax: $+31-30-2531145$. ation of phreatic water levels in the Netherlands. These maps comprise one of the main information layers of the Dutch soil information system, and the GWT surveys were done together with the soil surveys. The spatial objects in the Dutch geographical database are thus characterised in terms of both soil type and GWT. A comparable situation exists in many other countries, e.g. the United States ${ }^{3}$ and Russia ${ }^{4}$. In fact,

\footnotetext{
3 http://nasis.nrcs.usda.gov/documents/help/cosoilmoist.htm.

4 http://www.iiasa.ac.at/Research/FOR/russia_cd/soil_dat.htm.
} 
soil maps in all regions with shallow water tables benefit by an geographically associated characterization of the annual evolution of the water table depth, if only because these include the worlds most densely populated areas with the highest agricultural production. The soil and GWT maps have been surveyed for presentation scales 1:50,000 between 1961 and 1992. Since then, human practices (i.e. land reclamation, drainage, re-allotment, levelling and groundwater extraction) have caused changes in the groundwater levels and dynamics (Braat et al., 1989) and, thus, detoriation of the groundwater maps. For this reason, a cost efficient and fast update of the maps of GWT has become a priority issue in the Dutch soil data acquisition programme (Finke, 2000). One other priority was the update of the soil information data layers, which will be reported on elsewhere.

The GWT is a composite, ordinal variable (Bregt et al., 1992) based on classes (Fig. 1) of the mean highest water table (MHW) and mean lowest water table (MLW). The MHW is defined as the mean value of the three shallowest groundwater levels measured within each year over 8 or more consecutive years, where the measuring frequency is biweekly. The MLW is defined likewise with the deepest groundwater levels. The mean spring water table (MSW) is

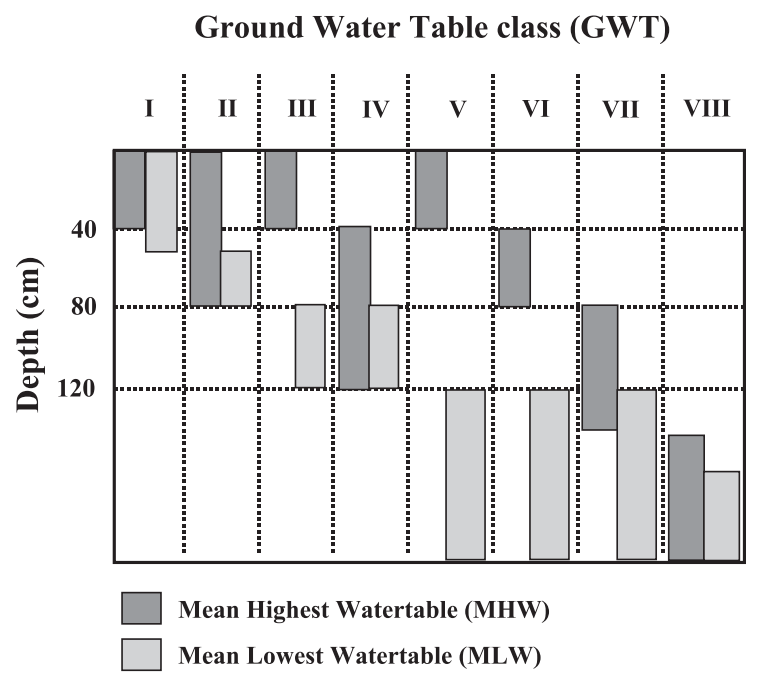

Fig. 1. Relation between groundwater table class (GWT) and mean highest water table (MHW) and mean lowest water table (MLW). defined likewise with the groundwater levels measured at three dates nearest to April 1. In this paper, all groundwater levels are phreatic, which means that the groundwater levels are the surface at every point of which the water pressure is atmospheric.

Because the combined soil/GWT survey was organised by map sheet and took 31 years, the necessary monitoring periods of 8 or more years to calculate MHW and MLW as a basis for GWT do not necessary overlap. Also, it has been shown (e.g., Knotters and Bierkens, 2000) that the precipitation deficit is a major driving force for groundwater fluctuations under Dutch circumstances. Thus, the asynchronicity in monitoring periods in combination with weather differences may have caused some systematic GWT differences between map sheets. A possibility to overcome this problem would be to base future MHW and MLW estimates on a longer measurement period of 30 years (the climatic period).

In spite of these shortcomings, the existing GWT maps are still frequently used. Nevertheless, a stakeholder survey showed (Finke et al., 1999; Table 1) that a quantitative description of more aspects of groundwater level fluctuations was needed in order to support a wider range of applications of the soil map (Table 1). Another stakeholders' wish was that an indication of the accuracy of the most important parameters (MHW, MLW and MSW) should be added.

Thus, there were three major reasons to change the way the groundwater dynamics should be mapped:

(i) the update of GWT maps should be cost efficient and fast;

(ii) the resulting maps should reflect the effect of weather variation within the climatic period ( 30 years) given the current water management;

(iii) an extended set (quantitative) parameters describing groundwater dynamics, with quantified accuracy, was needed.

Taking these three reasons as research objectives, we designed and applied a method to map the target parameter set resulting from the stakeholder survey (82 parameters; Table 1). The parameters are together referred to as the groundwater dynamics set (GD set). Each one of the GD parameters should, for the purpose of backward compatibility with existing 
Table 1

Prioritised parameters (and some applications) that describe aspects of groundwater dynamics as identified in a stakeholder survey (after Finke et al., 1999)

\begin{tabular}{|c|c|c|c|}
\hline Name & Description & $\begin{array}{l}\text { Example of application of parameter } \\
\text { (always in conjunction with soil data) }\end{array}$ & $\begin{array}{l}\text { Number of } \\
\text { mapped } \\
\text { parameters }\end{array}$ \\
\hline MHW & $\begin{array}{l}\text { mean highest water table; mean value over } 8 \text { or } \\
\text { more consecutive years of the three shallowest } \\
\text { groundwater levels measured within each year }{ }^{\mathrm{a}}\end{array}$ & phosphate binding capacity & 1 \\
\hline sdMHW & standard error of prediction of the MHW & & 1 \\
\hline MLW & $\begin{array}{l}\text { mean lowest water table; mean value over } 8 \text { or } \\
\text { more consecutive years of the three deepest } \\
\text { groundwater levels measured within each year }\end{array}$ & assessment of drought stress in field crops & 1 \\
\hline sdMLW & standard error of prediction of the MLW & & 1 \\
\hline MSW & $\begin{array}{l}\text { mean spring water table; mean value over } 8 \text { or } \\
\text { more consecutive years of the groundwater } \\
\text { levels at March 14, March } 28 \text { and April } 14 \\
\text { measured within each year }\end{array}$ & assessment of trafficability in early spring & 1 \\
\hline sdMSW & standard error of prediction of the MSW & & 1 \\
\hline GWT & groundwater table class (Fig. 1) & $\begin{array}{l}\text { soil map stratification for environmental } \\
\text { modeling }\end{array}$ & 1 \\
\hline FOE & $\begin{array}{l}\text { frequency of exceeding a given water table; the } \\
\text { number of periods }{ }^{\mathrm{a}} \text { within any } 1 \text { year that a } \\
\text { certain groundwater depth is exceeded. Based on } \\
\text { the estimated mean and standard deviation of the } \\
\text { water table in } 1 \text { year, and assuming a Normal } \\
\text { distribution function }\end{array}$ & $\begin{array}{l}\text { potential for development of specific } \\
\text { types of wetland or dry land vegetation }\end{array}$ & 2 \\
\hline REG & $\begin{array}{l}\text { water REGime; the expected water table } \\
\text { depth at a certain date }{ }^{\mathrm{a}} \text { in any } 1 \text { year }\end{array}$ & $\begin{array}{l}\text { assessment of water storage capacity } \\
\text { during the year }\end{array}$ & 24 \\
\hline REG5 & $\begin{array}{l}\text { water REGime } 5 \text { th percentile: the } 5 \text { th percentile of } \\
\text { the distribution of water table depths at a certain date }\end{array}$ & $\begin{array}{l}\text { assessment of minimal water storage } \\
\text { capacity during the year }\end{array}$ & 24 \\
\hline REG95 & $\begin{array}{l}\text { water REGime } 95 \text { th percentile: the } 95 \text { th percentile } \\
\text { of the distribution of water table depths at a certain date }\end{array}$ & $\begin{array}{l}\text { assessment of maximal water storage } \\
\text { capacity during the year }\end{array}$ & 24 \\
\hline SEEP & $\begin{array}{l}\text { indicator of the occurrence of seepage or leakage in any } \\
1 \text { year; estimated by the degree to which the difference } \\
\text { between average water table and local drainage basis can } \\
\text { be explained by the local precipitation surplus }\end{array}$ & $\begin{array}{l}\text { indicator of the occurrence of bicarbonate rich } \\
\text { upward water fluxes to predict vegetation type }\end{array}$ & 1 \\
\hline
\end{tabular}

${ }^{\mathrm{a}}$ All descriptions are based on a biweekly measuring frequency (the 14th and 28th of each month) and are representative for the current climate (i.e. reflect the weather variation over 30 recent years).

GWT maps, be mapped such that a presentation scale of 1:50,000 (or more detailed) is legitimate.

As the data environment in the Netherlands can be considered relatively rich, we took the following preassumptions as a basis to develop a mapping method:

(A) Some of the available (cf. Section 2) full-cover geographic data sets have predictive power to map GD parameters in the context of multiple linear regression (though it is a priori unknown which part of the data sets has predictive power and what the coefficients of the relation are);
(B) Since groundwater fluctuations may depend on specific combinations of soil type, land use landscape position, so may the sought regression relations. Thereto a functional stratification of the area to be mapped is taken as the basis for sampling and mapping.

The additional objectives of this paper are:

(iv) to test the quality of the mapping approach in 2 areas (10,000 ha and 179,000 ha);

(v) to explore the relation between cost and quality. 


\section{Material and methods}

\subsection{Primary data sources and consequences for mapping GD}

Since the target parameter set should reflect the effect of weather variation within the complete climatic period (30 years), it is important to have time series of groundwater measurements. The existing national network of monitoring piezometers has very few locations with complete data coverage over the last 30 years (Van Bracht, 2001), and also has too low spatial coverage to be the only basis for a mapping on detailed scales (Table 2). This means that both the temporal and spatial density of groundwater level measurements must be increased. In the Netherlands the precipitation deficit is the major driving force for groundwater fluctuations, and meteorological data are available for the climatic period. Time series analysis explaining groundwater fluctuation by precipitation deficit can therefore increase the temporal density of groundwater level estimates, while additional measurements can increase the spatial density.

However, groundwater fluctuations are known to vary geographically because of differences in soil type, landscape position, land use and (artificial) drainage situation even when the precipitation deficit is a geographical constant (e.g., Wösten et al., 1985; Knotters, 2001). This knowledge motivated the usage of existing data sources that reflect the geography of the above factors. Two types of geographic data were available:

1. Quantitative data such as the $25 \times 25 \mathrm{~m}^{2} \mathrm{DEM}$ of the Netherlands

2. Nominal and ordinal data such as soil type, GWT, land use and (hydro-) geology.

Nominal and ordinal data were predominantly used for stratification, while the quantitative data were used for prediction. The problems to be solved to make the data suitable for stratification and prediction are mentioned in Table 2; the activities needed to make the data usable for mapping are described in Section 2.3.

\subsection{Main activities and workflow}

The main activities that were identified (Table 2) to obtain maps of GD are presented in Fig. 2. The first series of activities translate the primary data set into a point-support GD data and a set of full-cover grid data with a common support of $25 \times 25 \mathrm{~m}^{2}$ (Section 2.3). This GD mapping set is the basis for the actual mapping procedure (Section 2.4).

Table 2

Usage of existing data sources and consequences for mapping GD

\begin{tabular}{|c|c|c|c|}
\hline Primary data source & Purpose of usage & Problem & Consequences \\
\hline \multirow[t]{2}{*}{ Phreatic head monitoring network } & $\begin{array}{l}\text { to obtain GD } \\
\text { characteristics } \\
\text { at point support and } \\
30 \text {-year extent }\end{array}$ & $\begin{array}{l}\text { 1. Insufficient temporal } \\
\text { coverage }\end{array}$ & $\begin{array}{l}\text { 1. Time series modelling } \\
\text { and simulation }\end{array}$ \\
\hline & & 2. Insufficient spatial coverage & 2. Additional phreatic measurements \\
\hline $\begin{array}{l}\text { Full-cover polygon maps } \\
\text { of soil, GWT and surface } \\
\text { (hydro-) geology }\end{array}$ & $\begin{array}{l}\text { stratification for } \\
\text { sampling and } \\
\text { mapping of GD }\end{array}$ & $\begin{array}{l}\text { 3. Stratification and sampling } \\
\text { criteria undefined }\end{array}$ & $\begin{array}{l}\text { 3. Development and application } \\
\text { of criteria for stratified sampling }\end{array}$ \\
\hline Full-cover grid $\mathrm{DEM}^{\mathrm{a}}$ & mapping of GD & $\begin{array}{l}\text { 4. Unknown and variable } \\
\text { hydrological relevance }\end{array}$ & $\begin{array}{l}\text { 4. Translate into set of full-cover } \\
\text { maps with hydrological relevance }\end{array}$ \\
\hline Drainage network maps & mapping of GD & $\begin{array}{l}\text { 5. Line elements have insufficient } \\
\text { spatial coverage }\end{array}$ & $\begin{array}{l}\text { 5. Translate to set of full-cover } \\
\text { drainage (density) maps }\end{array}$ \\
\hline Presence of subsurface drainage & mapping of GD & 6. Local measurements, no full coverage & 6. Make full-cover estimate \\
\hline
\end{tabular}

\footnotetext{
${ }^{\mathrm{a}}$ Digital Elevation Model.
} 


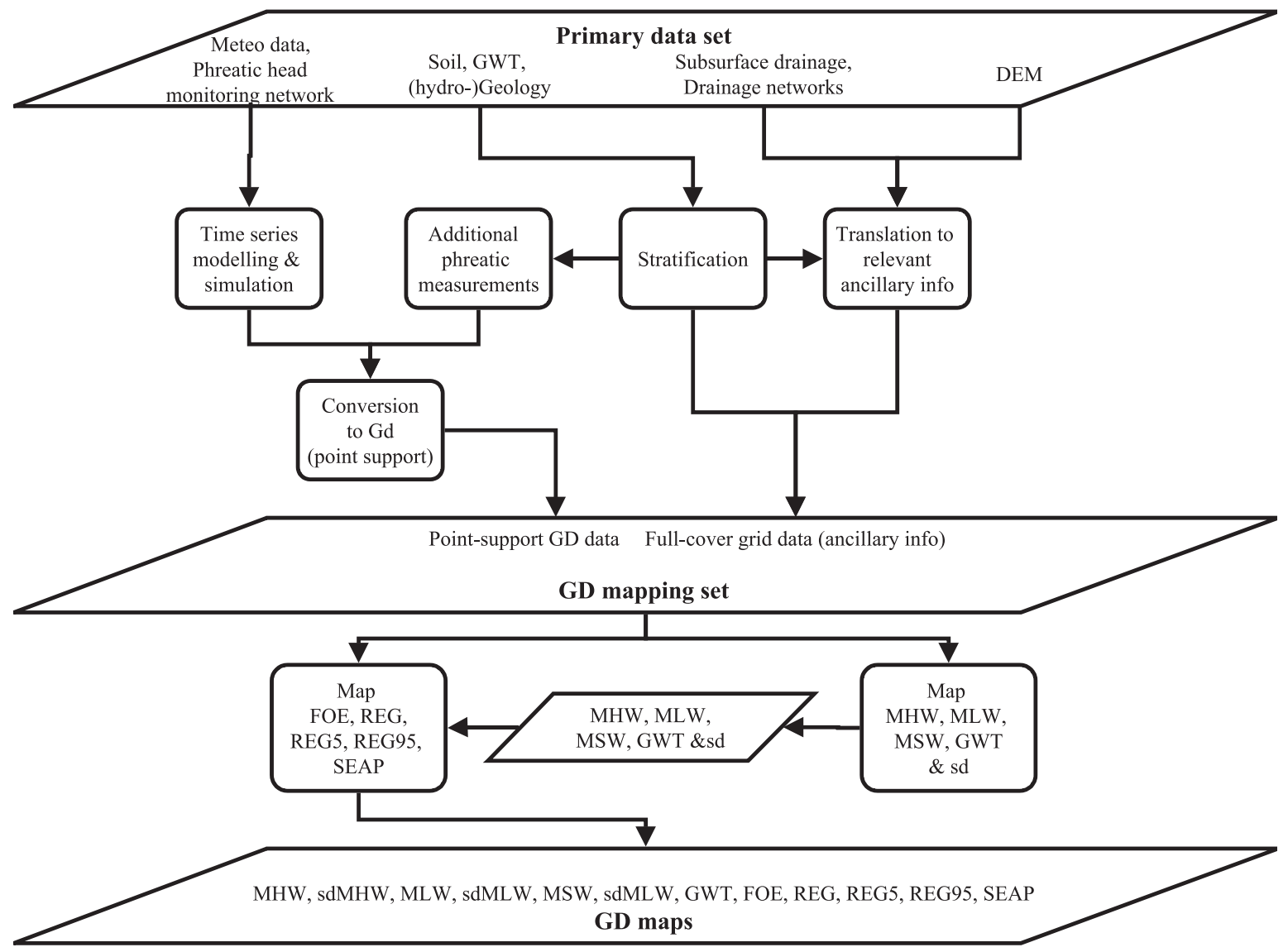

Fig. 2. Main activities and workflow for mapping groundwater dynamics (GD).

\subsection{Data conversion}

\subsubsection{Time series analysis}

Time series analysis is necessary, because in most networks few piezometers have been monitored for 5-8 years maximally, and time series are often incomplete as well. In summary, the approach was as follows:

1. Calibration of a transfer noise time series model;

2. Simulation of 30 -year series using the calibrated model;

3. Characterisation of the 30-year series in terms of the GD parameter set.

The relation between precipitation surplus (the precipitation minus the potential evapotranspiration) was parameterised on the available time series of groundwater levels and the complete time series of precipitation and evapotranspiration data. Groundwater data were screened for discontinuities in levels (usually caused by changed hydrological management practices) and location (displacement of the piezometer). In case of discontinuities, only the part of the time series after the discontinuity occurred was considered. Weather data were obtained from the closest weather station, usually within $20 \mathrm{~km}$ distance from the monitoring piezometer.

We used a simplified version of the transfer noise model described in detail by Bierkens and Knotters (1999):

$h_{t}=\delta h_{t-1}+\omega \mathrm{PE}_{t}$

$\left(n_{t}-c\right)=\phi\left(n_{t-1}-c\right)+a_{t}$ 
$h_{\mathrm{g}, t}=h_{t}+n_{t}$,

where $h_{t}$ is the groundwater level and $\mathrm{PE}_{t}$ is the precipitation surplus (both at day $t$ ), $\delta$ and $\omega$ are the weights assigned to the groundwater level at day $t-1$ and the precipitation surplus at day $t$, respectively. $a_{t}$ and $\left(n_{t}-c\right)$ are noise components with $c$ as a constant and $a_{t}$ as a white noise process; $\phi$ is the weight assigned to the noise component at day $t-1$. The deterministic component of the model (Eq. (1a), $h_{t}$ ) is added to the stochastic component (Eq. $\left.(1 \mathrm{~b}), n_{t}\right)$ to yield the actual transfer noise model (Eq. (1c), $h_{\mathrm{g}, t}$ ).

This transfer noise model is embedded in a Kalman filter, which optimises correspondence to measured groundwater levels. The coefficients $\delta, \omega, \phi$ and $c$ were calibrated using the KALTFN software (Bierkens and Knotters, 1999).

If calibration was successful, the model was used to simulate 100 realisations of 30 years of groundwater levels for each monitoring piezometer. Inputs comprised a complete 30-year time series of precipitation surpluses measured in the most nearby weather station, the calibrated coefficients and the noise term $a_{t}$. The resulting realisations of the complete time series were used to calculate the time series characteristics from the GD parameter set (Table 1).

\subsubsection{Stratification and sampling}

The purpose of stratification is to minimise the uncertainty of the GD maps. Hereto, areas must be identified that have characteristic (yet unknown) relations between ancillary information and the GD parameter set. The stratification was based on thematic a priori information by reclassification of individual map polygons of the Dutch 1:50,000 Soil and GWT map (de Bakker and Schelling, 1986). Where $1: 10,000$ and 1:25,000 maps were available as well, these were used. The stratification followed the following format:

1. Polygons were labelled on basis of the surface geological formation. If applicable, surface fault lines were used to split polygons.

2. These major units were subdivided on the basis of attributes of the original soil map polygons such as dominant soil texture, the occurrence of clayey layers or coarse sandy layers. Indicators of typical hydrological conditions either appearing on the original map of GWT, or on topographic maps as a typical drainage intensity or on land cover maps (e.g. peat reserves), were used for further subdivision.

3. The maps thus obtained locally showed fragmented patterns. The last step consisted of a local defragmentation such that landscape patterns (such as brook valleys, dry ridges, sand dunes) were preserved in the final stratification.

Depending on the scale of the landscape, the resulting strata usually occupied areas between 1000 and 5000 ha.

The strata served as the basic units for additional sampling in the field. Groundwater levels were measured at two dates and according to a purposive spatial sampling scheme.

One measurement was done near the date that groundwater levels are close to the MHW (usually near the end of the winter), the other measurement was done near the date that groundwater levels are close to the MLW (usually at the end of summer). Groundwater levels were measured in both the piezometers of the monitoring network and in a set of temporary piezometers. The method to obtain MHW, MSW and MLW values in the temporary piezometers was developed from the one described by te Riele and Brus (1991). Regression relations were fitted between the MHW, MLW and MSW and the measured water level in the permanent piezometer for the combinations of two dates as well as each one date separately Thus, for each temporary piezometer in which a summer and a winter measurement has been done, three regression models can be fitted for MHW as well as MLW and MSW:

$Y=\beta_{0}+\beta_{1} X_{1}+\beta_{2} X_{2}+\varepsilon$

where $Y$ is MHW, MLW or MSW, $\beta_{0}$ is the regression constant, $\beta_{1}$ is the coefficient for the measurement at date $X_{1}$ and $\beta_{2}$ is the coefficient for the measurement at date $X_{2}$. The three possible models are: $\beta_{1}=0 \wedge \beta_{2} \neq$ $0 ; \beta_{1} \neq 0 \wedge \beta_{2}=0$; and $\beta_{1} \neq 0 \wedge \beta_{2} \neq 0$. The best model for each MHW, MSW or MLW for a specific combination of two measurement dates was chosen by the 
following procedure based on Mallow's Cp (Mallows, 1966):

1. Calculation of Mallow's Cp:

$\mathrm{Cp}=\mathrm{SS}_{\text {res }} / s^{2}-n+2 p$

where $\mathrm{SS}_{\text {res }}$ is the sum of squared errors of predicted versus measured MHW (MSW, MLW) of the analysed model, $s^{2}$ is the error variance of the complete model (in this case: with $\beta_{1} \neq 0 \wedge \beta_{2} \neq$ $0), n$ is the number of sampled piezometers from the permanent network, and $p$ is the number of coefficients of the model ( $p=2$ or 3 , since models containing only a constant are not considered).

2. Selection of models with a Cp smaller than $(p+3)$;

3. Selection of the model(s) with the smallest number of coefficients;

4. Selection of the model with the smallest error variance.

The selected model was applied to the measured groundwater levels in the temporary piezometers, resulting in an estimate of the MHW, MLW and MSW and associated standard errors. Since the temporary piezometers have a limited depth $(250 \mathrm{~cm})$, part of the data set of measured groundwater tables consists of censored ("deeper than") observations. These censored observations were replaced by maximum-likelihood estimates before applying the selected regression models. Maximum likelihood estimates were obtained according to a method given by Cohen (1991). The corrected distribution function including the censored observation is given by:

$\sigma^{2}=s^{2}+\lambda(h, \alpha) \times(\bar{x}-T)^{2}$

$\mu=\bar{x}-\lambda(h, \alpha) \times(\bar{x}-T)$,

where $s^{2}$ is the variance of the non-censored observations, $\bar{x}$ is de mean value of the non-censored observations, $T$ is the censored depth (e.g., $250 \mathrm{~cm}$ ), $h$ is de fraction of the sample that is censored, $\alpha=s^{2} /(\bar{x}-T)^{2}$ and $\lambda$ is tabulated for specific values of $h$ and $\alpha$ (cf. Cohen, 1991, pp. 21-24). The maximum likelihood value for a censored observation is obtained by numerical integration of the right tail (greater than T) of the corrected distribution.
Spatial allocation of the temporary piezometers was done by stratum. Inside each stratum the number of temporary piezometers was minimally 25 , with an overall average sampling density of 1 per $1 \mathrm{~km}^{2}$. The sampling locations were chosen to reflect the distribution of local drainage depths as well as homogeneous spatial coverage. The local drainage depth was estimated in GIS by interpolating the known water levels in ditches and brooks with inverse distance weighted interpolation and subtracting these values from the $25 \times 25 \mathrm{~m}^{2} \mathrm{DEM}$. The distribution of local drainage depths was log-transformed, and one $25 \times 25$ cell from each $X$ th percentile of the distribution was chosen such that a minimal distance to the previously chosen grid cell was maintained. The log-transformation was done to put some emphasis in sampling the wetter terrain parts, since the stakeholders expressed the wish to have the highest accuracy of GD maps in the wettest terrain parts. The value of $X$ depended on the sample size $N$ for the stratum (e.g., when $N=25$, $X=4 \%$ ).

\subsubsection{Ancillary information}

Ancillary information is necessary as predictor in the regression approach for mapping GD. All ancillary parameters must have full geographic coverage in the non-urban parts of the area, and should have hydrological relevance. Also, these predictive parameters should be of quantitative nature to be applicable in regression equations, thus be either on an indicator ( 0 / 1) scale or on the ratio scale. From the available primary data sets (Table 2) we derived groups of ancillary data. Ancillary data were grouped into seven groups, because it was expected that subsets of these data would be highly correlated. Allowing highly correlated data as predictors would cause redundancy in the regression models. This expectation was supported by scattergrams (Fig. 3). The seven groups were:

1. Absolute altitude. This parameter is derived directly from the $25 \times 25 \mathrm{~m}^{2}$ DEM.

2. Altitude relative to a local mean. This parameter accounts for the effect that the phreatic surface often cannot follow intricate relief patterns. In this case, relative altitude can explain part of the variation of groundwater table depth. Relative altitude is calculated in GIS by subtracting the absolute altitude from each grid cell in the DEM 


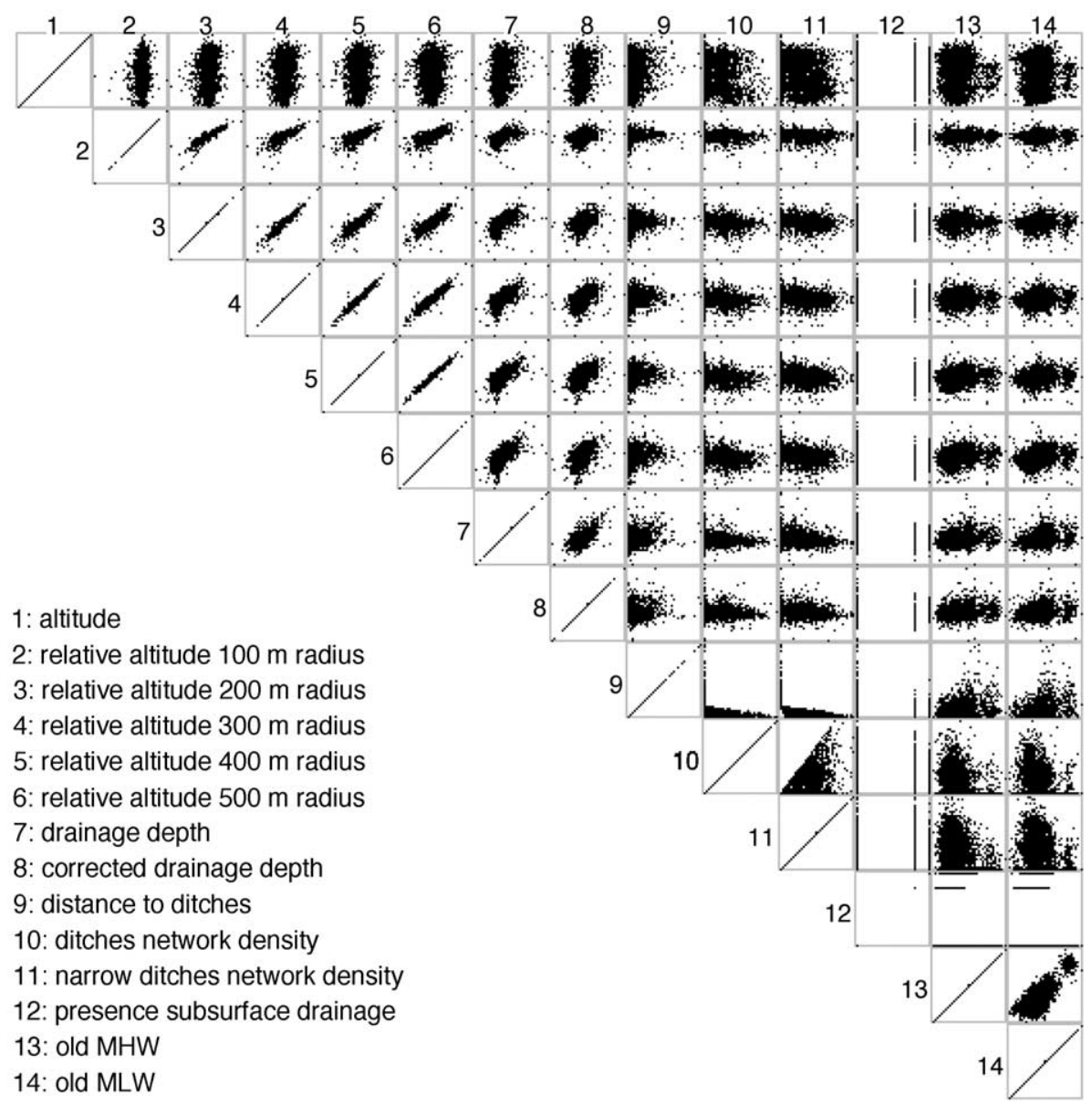

Fig. 3. Scatter plots between ancillary data in 3478 sampled locations.

from the local mean altitude within a search radius (Fig. 4a). We produced five relative altitude maps by calculation for five search radii: 100, 200, 300, 400 and $500 \mathrm{~m}$.

3. Local density of the drainage network. This parameter accounts for the effect that an intensive drainage network is able to reduce the occurrence of shallow water tables after rainfall events to a short period. Alternatively, as a drainage network is purposive, it may be an indicator of the occurrence of shallow water tables. Local density of the drainage network is calculated in GIS by counting the grid cells from the DEM within a search radius that are intersected by a ditch or brook (Fig. 4c). The drainage network is obtained from the $1: 10,000$ topographic map of the Netherlands. We made a distinction between narrow ditches and wide ditches to produce two parameter maps.

4. Local drainage depth. This parameter corresponds to the groundwater levels that the water management boards expect to achieve with the drainage infrastructure and management practices. The local drainage depth was mapped using the $25 \times 25 \mathrm{~m}^{2}$ DEM, the 1:10,000 topographic map and maintained water levels in ditches if available. First, the drainage basis was established in GIS by taking the deepest value within a $100 \times 100 \mathrm{~m}^{2}$ window of the DEM that intersects with a line element in the drainage network map as a first estimate of drainage basis, and the subsequent spatial interpolation of these values (Fig. 4b) with inverse distance weighted interpolation. The difference 


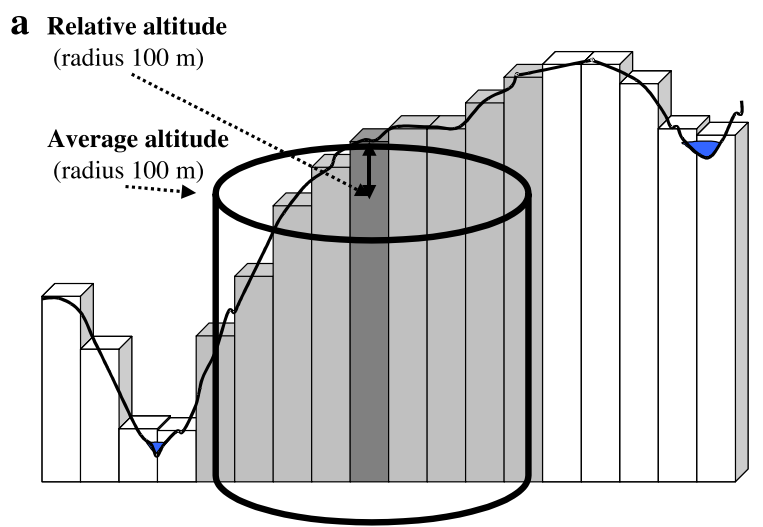

C Drainage density primary ditches

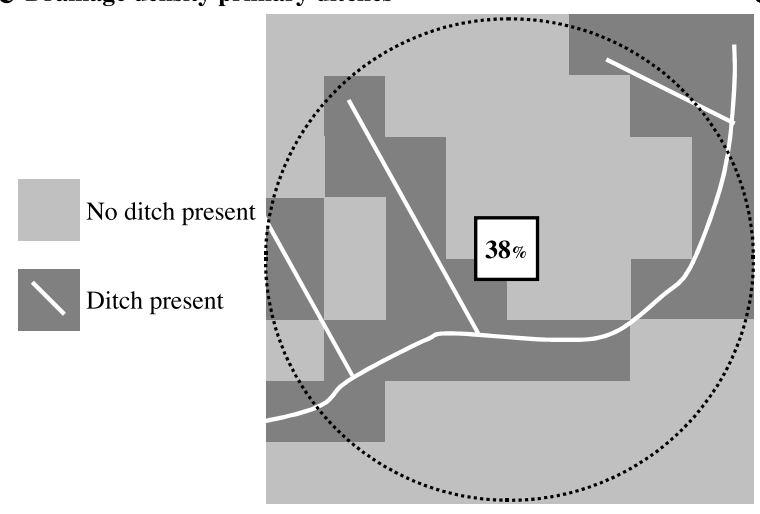

b Interpolated drainage basis

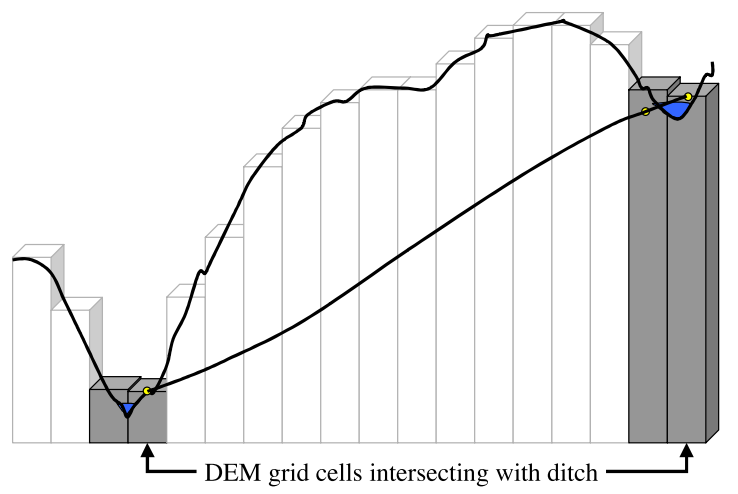

d Distance to ditch

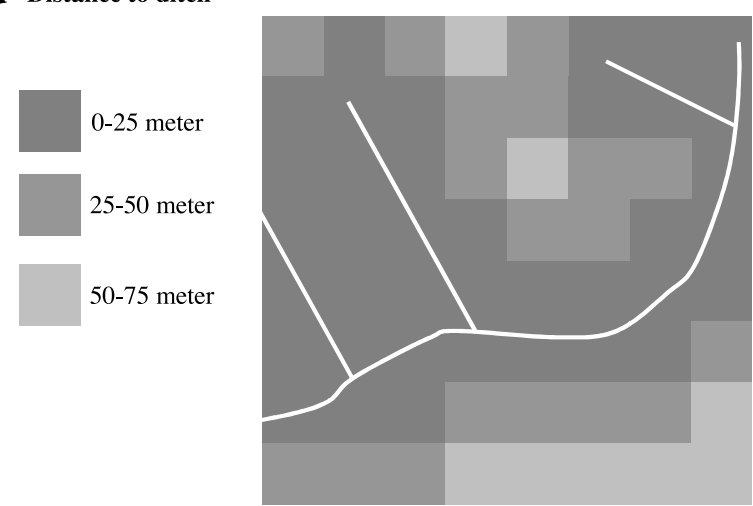

Fig. 4. Derivation of ancillary information from DEM and topographic maps.

between altitude from the DEM and drainage basis then gave the drainage depth. Measured actual water levels in the ditches during the field survey were used to correct the drainage depth map. Hereto, at the observation locations, the difference between GIS-estimated and measured drainage basis was calculated. Subsequently, this difference was interpolated with inverse distance weighted interpolation and the resulting map of differences was added to the GIS map to result in the corrected map. Both the GIS map and the corrected map of drainage depth were used as ancillary information.

5. Distance to local ditches. This parameter accounts for the effect that groundwater levels are increasingly shallow at larger distances from draining ditches (and, vice versa, that groundwater levels are increasingly deep at larger distances from water supply ditches). By interpolating the distance to ditches from the 1:10,000 topographic map this map is easily obtained (Fig. 4).

6. Presence of subsurface drainage. The presence or absence of subsurface drainage is the local farmers' response to the occurring groundwater levels in combination to the land use at the field scale. The presence of drains will deepen the groundwater levels in the moist part of the year. This indicator parameter was mapped using the $25 \times 25 \mathrm{~m}^{2}$ cell size Land Cover Map of the Netherlands (Thunnissen et al., 1992) and the existing GWT map, using an expert classification scheme developed for a national extent hydrological model (Massop et al., 2000).

7. Old $M H W$ and $M L W$ from the soil map 1:50,000. Though the GWT maps are outdated, spatial patterns of updated maps may still be comparable to those of the original maps. For this reason, we 
produced maps of the old MHW and MLW as ancillary information. For each GWT polygon of the original GWT map, the class average MHW and MLW was assigned. This map would have discontinuities at polygon boundaries, which is not plausible in a hydrological sense. Therefore, the MHW and MLW maps were downscaled such that $70 \%$ of the area of each polygon would fall within the class boundaries of the GWT for MHW and MLW (Fig. 1). The value of $70 \%$ represents the assumed map purity of the original GWT map. Downscaling was done by projection of the altitude range of the 15 th to 85 th percentile of the $25 \times 25$ $\mathrm{m}^{2}$ DEM within the map polygon on the class width of MHW (or MLW) defined by GWT. Higher altitudes within a GWT polygon correspond with deeper MHW of MLW. The remaining 30\% of the area (usually near polygon boundaries) were filled with MHW (or MLW) data by spatial interpolation (inverse distance weighted interpolation).

\subsection{Mapping $M H W, M L W$ and $M S W$}

\subsubsection{Regression analysis}

We fitted all possible models between point values of Gd parameters and the groups of ancillary infomation as predictors by weighted regression. As weights we took the factor $\left(f /\left(1+s^{2}\right)\right)$, where $s^{2}$ is the error variance of the MHW, MLW or MSW values from the point data set, and $f$ is a factor that makes the weights sum up to the sample size. Thus, the weights vary by the quality of the regression point estimates, based on either the well-timed measurements or the time series in permanent piezometers, and are highest for the estimates in the permanent piezometers. The best regression model is selected using Mallow's Cp statistic in a procedure comparable to that in Section 2.3.2. A complication in the model selection is the fact that correlated predictors were combined into groups (Section 2.3.3). Only one member of each group may enter one regression equation. The total number of regressions $M$, for each stratum and MHW, MSW and MLW, is defined by:

$$
M=\prod_{i=1}^{N} G_{i} \times \sum_{R=1}^{N} \frac{N !}{(N-R) ! \times R !},
$$

where $N$ is the number of groups and $G_{i}$ is the number of predictors in group $i$.

In the current study (Section 2.3.2), $N=7, G_{2}=5$, $G_{3}=2, G_{4}=2, G_{7}=2$ and other $G_{i}=1$, so $(30 \times 127=) 3810$ regression models must be evaluated. All models contain a regression constant as well. As $s^{2}$ value for the calculation of Mallow's Cp we took the best performing complete model, that is, the model with lowest error variance from the subset of fitted models with $N$ predictors.

The best found model is then applied to predict MHW, MLW or MWS at all $25 \times 25 \mathrm{~m}^{2}$ grid cells at which the ancillary information is known.

The uncertainty of a prediction $\hat{y}$ in a non-sampled location is quantified by:

$\operatorname{var}\left(\hat{y}_{0}\right)=\sigma^{2}\left(1+x_{0}^{\prime}\left(X^{\prime} W X\right)^{-1} x_{0}\right)$,

where $\sigma^{2}$ is the residual variance of the model, $x_{0}$ is the $(p+1)$ vector of $p$ predictors (and the value 1 for the regression constant), $X$ is the $(n \times(p+1))$ matrix with $(p+1)$ predictors in the columns and with $n$ observations on which the regression equation was fitted in the rows and $W$ is the $(n \times n)$ matrix containing the weight assigned to each observation.

In Eq. (6), the component $\sigma^{2} x^{\prime}\left(X^{\prime} W X\right)^{-1} x_{0}$ represents the effect of the uncertainty of the regression parameters, while the component $\sigma^{2} \times 1$ represents the effect of predicting to non-sampled locations.

\subsubsection{Kriging standardised residuals and error mapping}

The error component $\sigma^{2}$ of the regression model (Eq. (6)) is obtained for each stratum, but it is not necessarily spatially constant. If the residuals of the regression function show spatial autocorrelation, then they can be mapped using geostatistical methods. In this case, $\sigma^{2}$ in Eq. (6) becomes a function of the location and the sample data configuration. At the location of a measured MHW (or MLW, MSW), the value of $\sigma^{2}$ becomes 0 . The further a location is away from sampled points, the larger the value of $\sigma^{2}$. This is elaborated into an error model. It should be noted that this combination of regression and spatial interpolation to calculate uncertainty is not fully consistent, since in ordinary least squares regression it is assumed that residuals are not correlated. However, it can be shown that the error model we present hereunder 
slightly overestimates true error and will thus yield a conservative estimate of map quality.

We calculated the residuals of the regression models on the sampled points, and standardised these by division by the value of $\sigma$ for the sampling stratum. The reason for standardisation is that residual variances are not constant for the strata. Semivariograms were fitted to the standardised residuals, and the residuals were mapped using simple kriging, because the mean of the residuals is known (e.g., Cressie, 1993). Predictions of the standardised residual $r_{\text {stand }}$ and associated kriging error $\operatorname{var}\left(\hat{r}_{\text {stand }}\right)$ were obtained for each $25 \times 25 \mathrm{~m}^{2}$ grid cell by using the KT3D routine from GSLIB (Deutsch and Journel, 1998). Destandardisation of the interpolated residuals and of the kriging error was done afterwards, resulting in values of $\hat{r}$ and $\operatorname{var}(\hat{r})$ for each grid cell. The actual predicted values for MHW (MLW, MSW) and associated uncertainty were then calculated by:

$\hat{y}_{0}=X \beta+\hat{r}$

$\operatorname{var}\left(\hat{y}_{0}\right)=\sigma^{2} x_{0}^{\prime}\left(X^{\prime} W X\right)^{-1} x_{0}+\operatorname{var}(\hat{r})$,

respectively, where $\beta$ is the $(p+1)$ vector of regression coefficients including the constant. Thus, the error components, due to uncertainty of the regression parameters and to the uncertainty associated to interpolated residuals, are mapped separately. The slight overestimation of the error model lies in the fact that $\sigma^{2}$ is in fact zero near sample points whereas in the error model it is a constant for the whole stratum.

The GWT is mapped from values of MHW and MLW by classification according to Fig. 1.

\subsection{Mapping other GD parameters}

\subsubsection{Annual and fortnightly distribution parameters}

These 74 parameters describe the expectation of the annual distribution $(2 * \mathrm{FOE})$ and the expectations of characteristics of the fortnightly distributions (24*REG5, 24*REG, 24*REG95). It was expected that these parameters would show correlation to the MHW, MLW and MSW, and therefore a simplified mapping method was applied:

1. For each major unit of the stratification (i.e. the surface geological formations, Section 2.3.2), the
74 parameters are obtained from simulated (complete) time series in permanent piezometers.

2. A regression relation is fitted to each one parameter, using MHW, MLW and MSW as predictors.

3. This regression relation is applied to all $25 \times 25 \mathrm{~m}^{2}$ grid cells for which MHW, MLW and MSW had become available by mapping.

The fortnightly distribution parameters together are usually referred to as a regime graph and its bandwidth and can be constructed per grid cell directly from the result of step 3. The annual distribution is usually presented graphically as a cumulative frequency distribution (the FOE graph), which shows the number of days that a specific groundwater level is exceeded. Assuming a normal distribution, the mean $\mu$ and standard deviation $\sigma$ of the water table depth in 1 year mapped in step 3 still have to be converted using:

$d(x>a)=365\left(1-\frac{1}{\sigma \sqrt{2 \pi}} \int_{-\infty}^{a} \mathrm{e}^{-1 / 2\left(\frac{(x-\mu)}{\sigma}\right)^{2}} \mathrm{~d} x\right)$,

where $d$ is the expected number of days in any future year that shallower groundwater levels than $a \mathrm{~cm}$ depth occur.

\subsubsection{Seepage}

The occurrence of seepage is indicated when the yearly average groundwater depth in case of zero precipitation is shallower than the local drainage depth. To map the occurrence of seepage, we based ourselves on previous research by Knotters and Bierkens (2000). The seepage flux $q$ is calculated via:

$q=(c-d) / \gamma$,

where $c$ is the yearly average groundwater depth [cm] in case of zero precipitation and is available from time series modelling (Eq. (1b)) for all permanent piezometers, $d$ is the drainage depth $[\mathrm{cm}]$ which is an ancillary variable (Section 2.3.3) and $\gamma$ is the drainage resistance [d] which can be calculated from the calibrated parameters $\omega$ and $\delta$ of the time series model via (Knotters and Bierkens, 2000):

$\gamma=\omega /(1-\delta)$ 


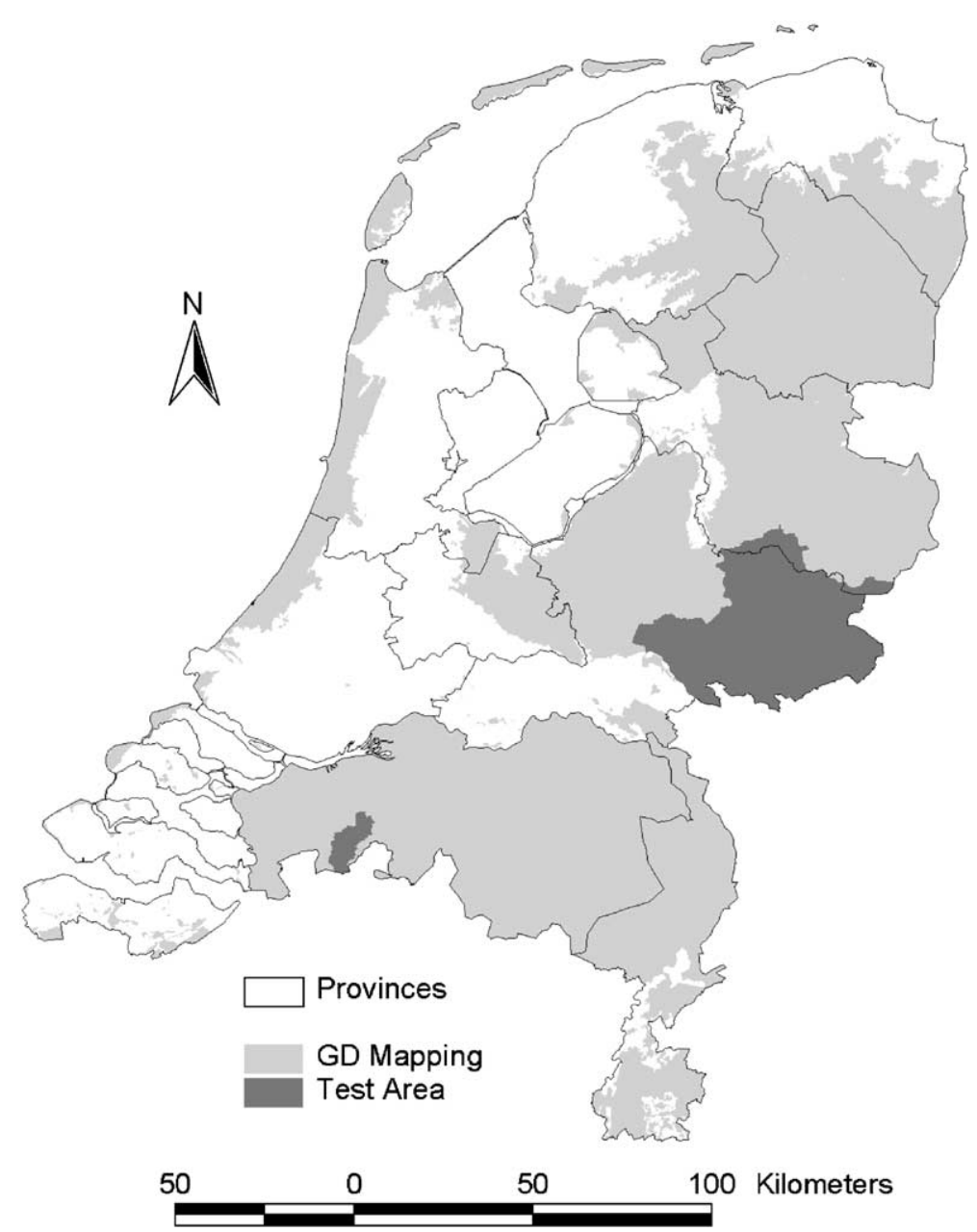

Fig. 5. Areas where GD parameter set is mapped (grey), and where map quality was tested (black).

Thus, seepage fluxes were calculated for the permanent piezometers, and regression relations were then sought for the major units of the stratification, to predict $q$ from MHW, MLW, MSW and $d$. These relations were then applied for the whole area. Values of $q$ were transformed into three classes, "seepage", "intermediate" and "leakage", to avoid pseudo-accuracy.

\subsection{Testing map quality}

The current GD mapping projects cover a total of $1,790,000$ ha (i.e. $55 \%$ of the Netherlands). The resulting maps of GD were evaluated using independent test sets in 2 areas (Fig. 5). As the GD parameters MHW, MLW, MSW and GWT are the most frequently used, the evaluation of map quality concentrated on these parameters. In the 10,000 ha test area, 30 locations were randomly selected, in the 179,000 ha test area 92 locations. These locations were distributed proportionally over most strata and at random within each stratum, excluding those strata with deep groundwater levels. In the validation points, MHW, MLW and MSW were determined by well-timed measurements according to the procedure in Section 2.3.2. Three error statistics were calculated:

$\mathrm{ME}=\frac{1}{n} \times \sum_{i=1}^{n}\left(y_{i}-\hat{y}_{0, i}\right)$ 
$\operatorname{RMSE}=\sqrt{1 / n \times \sum_{i=1}^{n}\left(y_{i}-\hat{y}_{0, i}\right)^{2}}$

$\mathrm{RMPEV}=\sqrt{1 / n \times \sum_{i=1}^{n} \operatorname{var} \hat{y}_{0, i}}$,

where the RMPEV follows directly from the mapping (Eq. (7b)), while ME and RMSE are based on differences between the values on the map $\left(\hat{y}_{0, i}\right)$ and in validation points $\left(y_{i}\right)$.
Furthermore, the quality of GWT maps was determined by calculation of the map purity (the \% of the area where mapped GWT and validation GWT are the same, estimated in locations of the test set).

2.7. Exploring the effect of sampling density on map quality and mapping cost

From Eq. (7b) it follows that uncertainty in the regression parameters and uncertainty due to kriging

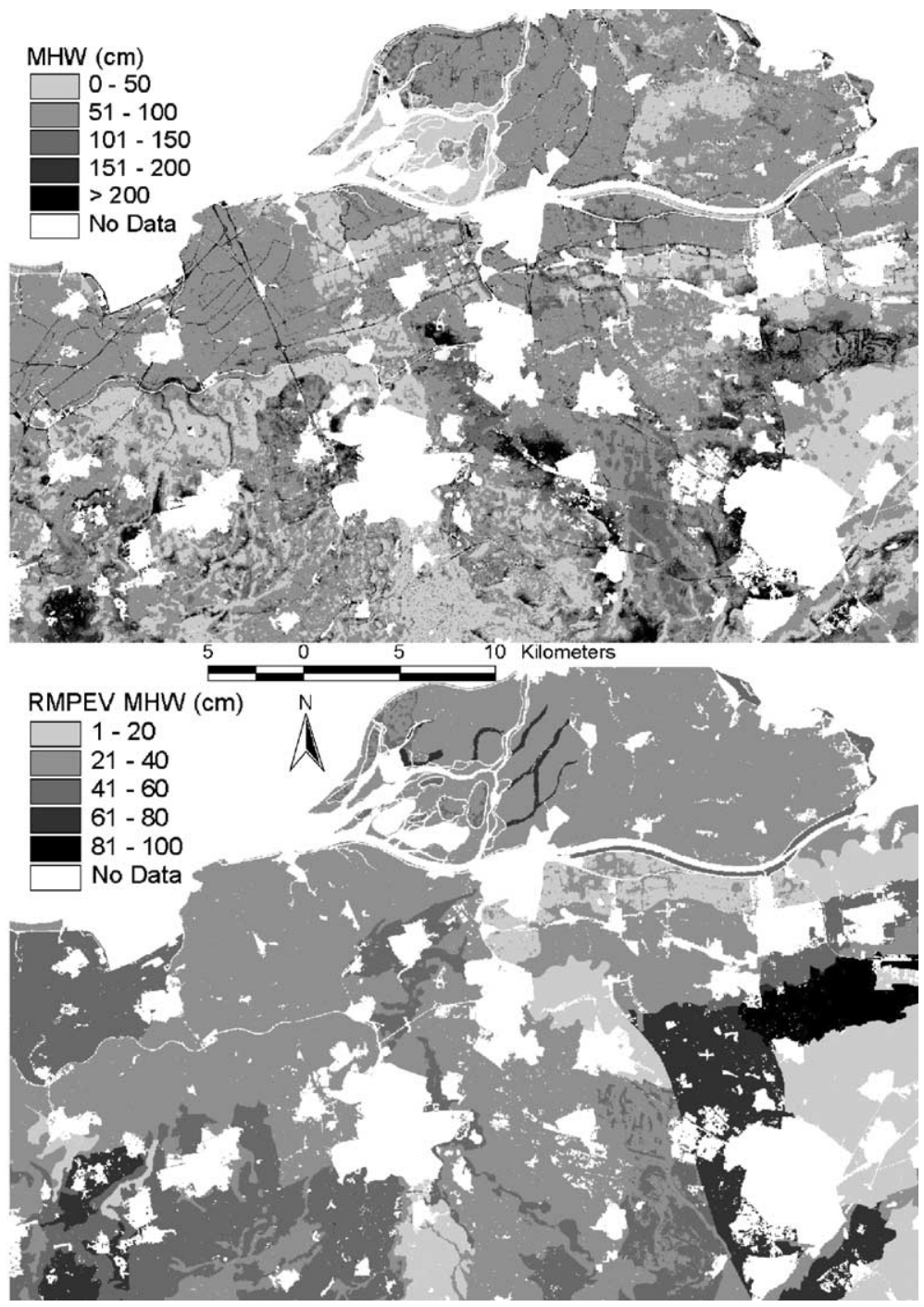

Fig. 6. Map of MHW and associated uncertainty. 
the standardised residuals are mapped separately. Changing the sampling density (i.e. the number of MHW, MLW and MSW estimates at the point support) will affect both of these uncertainty components. We applied the rule of thumb that the uncertainty component due to uncertainty in the regression parameters will decrease by a factor 2 when the sample size $N$ increases with a factor 4 . In case of the GD mapping procedure, this rule of thumb can serve as a worst case scenario. At any new (larger) sample size $N_{2}$, a new "best" regression model for a stratum would be selected and fitted that may be better (but is never worse) than the regression model at sample size $N$. The uncertainty component due to the kriging of standardised residuals can be assessed at individual locations using the variograms fitted for $N$ and the sample configuration corresponding to $N_{2}$ (cf. Burgess and Webster, 1980). By combining both of the uncertainty contributions for a sufficiently large number of locations, the effect of sampling density on the map quality parameter RMPEV can be evaluated for each stratum separately. Associated cost were easily estimated, since the cost of field work dominate total cost (Finke, 2000) and the major difference between two sampling densities is the amount of fieldwork to be done.

\section{Results and discussion}

\subsection{Data and map quality}

The MHW, MLW and MSW maps (Fig. 6) are associated with maps of the root prediction error variance (RPEV) as calculated using Eqs. (7a) Eq. (7b). RPEV values are also known for the point estimations of these three parameters. Fig. 7 shows that mapping (regression followed by kriging standardised resuduals) clearly contributes to uncertainty. This increase in uncertainty may be partly due to errors in the $25 \times 25$ DEM that is used to generate ancillary information used as predictors in the mapping procedure. The effect of errors in the DEM on uncertainty in predictions is a subject for further research. Point support values of RPEV are almost exclusively in the class between 0 and $20 \mathrm{~cm}$, while the mapped MHW, MLW and MSW for $25 \times 25 \mathrm{~m}^{2}$ cells have RPEV of less than $40 \mathrm{~cm}$ in more than $60 \%$ of the area. The highest values of RPEV are found in the strata with the deepest water table depths. This is mainly due to the fact, that censored observations (deeper than $250 \mathrm{~cm}$ ) had to be used for mapping in these areas. The most favourable values of RPEV occur in strata where groundwater levels are relatively shallow and near sampling locations.

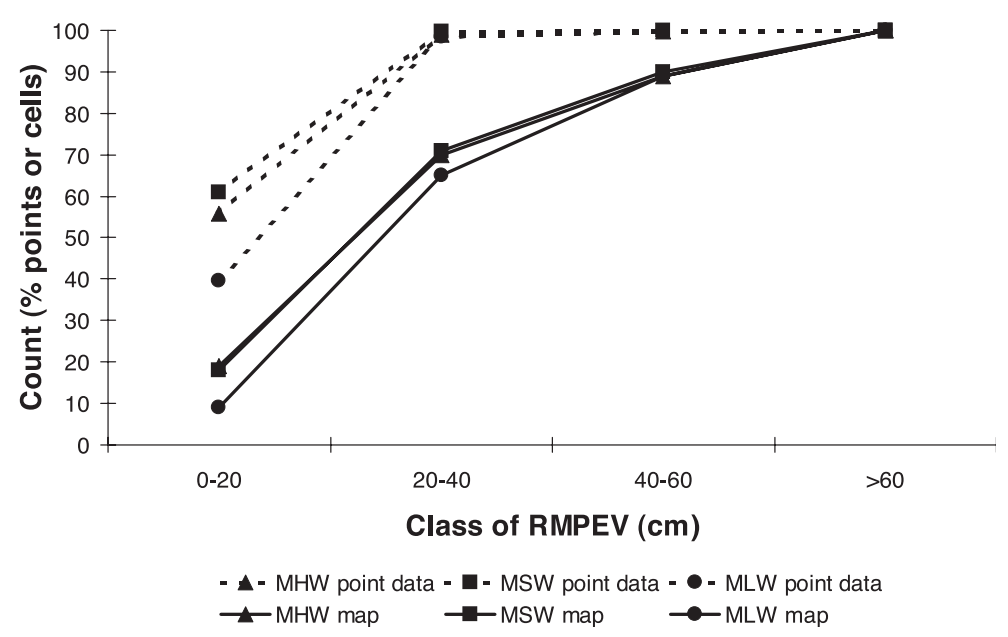

Fig. 7. Cumulative distributions of root prediction error variances (RPEV) of MHW, MLW and MSW point data (dashed lines) and maps (solid lines). 
Table 3

Validation results

\begin{tabular}{lllll}
\hline GD parameter & $\begin{array}{l}\text { Test } \\
\text { statistic }^{\text {a }}\end{array}$ & SI unit & $\begin{array}{l}10,000 \text { ha } \\
\text { area }(n=30)\end{array}$ & $\begin{array}{l}179,000 \text { ha } \\
\text { area }(n=91)\end{array}$ \\
\hline MHW & ME & $\mathrm{m}$ & 0.03 & 0.04 \\
MHW & RMSE & $\mathrm{m}$ & 0.37 & 0.27 \\
MHW & RMPEV & $\mathrm{m}$ & n.d. & 0.28 \\
MLW & ME & $\mathrm{m}$ & 0.06 & 0.07 \\
MLW & RMSE & $\mathrm{m}$ & 0.35 & 0.42 \\
MLW & RMPEV & $\mathrm{m}$ & n.d. & 0.37 \\
MSW & ME & $\mathrm{m}$ & 0.02 & 0.05 \\
MSW & RMSE & $\mathrm{m}$ & 0.32 & 0.28 \\
MSW & RMPEV & $\mathrm{m}$ & n.d. & 0.30 \\
GWT & Purity new & - & $37 \%$ & $62 \%$ \\
& map (\%) & & & \\
GWT & Purity old & - & $13 \%$ & $20 \%$ \\
& map (\%) & & & \\
\hline
\end{tabular}

$\mathrm{ME}=$ mean error (positive value: validation groundwater level = deeper than mapped level); RMSE = root mean squared error; $\mathrm{RMPEV}=$ root mean prediction error variance; n.d. $=$ not determined.

${ }^{\mathrm{a}}$ Described in the text.

Results of independent quality tests (Table 3 ) in the 10,000 and the 179,000 ha area (Fig. 5) show, that values of ME are always close to 0 , which indicates that the maps have no bias. Values for RMSE and RMPEV only differ by a few $\mathrm{cm}$, which indicates that the uncertainty measure mapped by the RPEV parameter gives an accurate estimate of the map quality.

The purity of the new GWT map is better in both tested areas than that of the old map, although actual values of map purity differed strongly between the tested areas. This may be caused by (i) greater hydrological changes in one area than in the other, or (ii) a lesser initial quality of the original GWT map. These factors both decrease the predictive power of some ancillary information, and thus the potential to estimate actual spatial patterns of Gd parameters.

\subsection{Sampling density, quality and cost}

The total uncertainty in the maps of MHW, MLW and MSW was found to be largely due to the prediction error variance by kriging standardised residuals to non-visited locations. In the area mapped so far $(>500,000 \mathrm{ha})$, the uncertainty in the regression parameters comprised only $6 \%$ of total uncertainty. However, if different ancillary information would become available with high predictive power, uncertainty would strongly decrease because the residuals would be smaller. Taking the currently available ancillary information, increasing the sampling density (Fig. 8) will

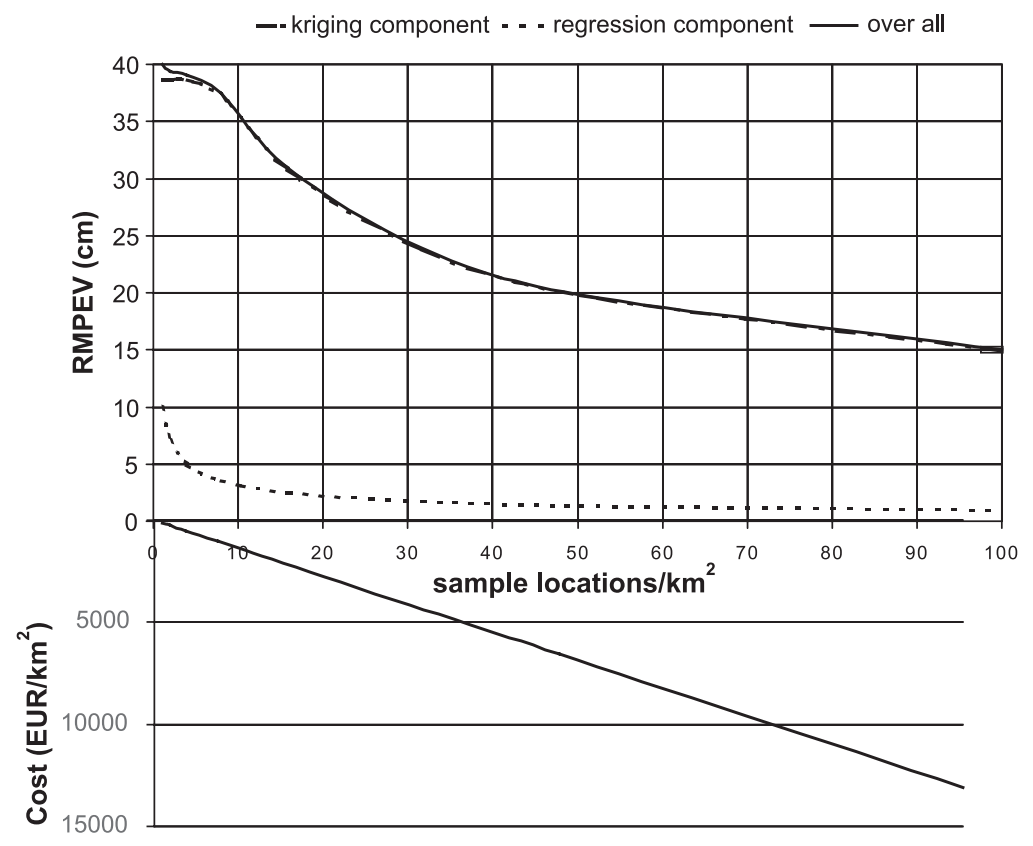

Fig. 8. Relation between sampling density, root mean prediction error variance (RMPEV) due to two uncertainty components and mapping cost. 
therefore most strongly affect the RMPEV via the kriging component. Thus, the variogram and sample configuration will be most important. The level of the semivariance at short lag distances will determine the maximal quality that can be attained. Unfortunately, short range variation is not well known from the current mapping practices since sampling densities are near to $1 / \mathrm{km}^{2}$, but it can be assumed that maximum quality levels will be near the RPEV values for point estimates for MHW, MLW and MSW (Fig. 7). Mapping cost of the complete GD parameter set are linear with sampling density, and were approximately EUR $150 / \mathrm{km}^{2}$ at the actual sampling density of $1 / \mathrm{km}^{2}$. Mapping (only) the GWT parameter with the traditional free survey would have cost approximately EUR $230 / \mathrm{km}^{2}$, because fieldwork is more intensive.

\subsection{Portability of methods to other parameters and areas}

We feel that the proposed mapping method, using ancillary data such as elevation data, derived terrain attributes and thematic information such as soil maps, is applicable to a wider range of soilrelated parameters than just the Gd parameter set. The dependency to landscape position, land use and drainage situation may exist for many soil parameters, and this recognition of the value of terrain modelling has already led to various attempts to map various soil parameters (e.g., Gessler et al., 2000). Our method is new in the sense that it incorporates the temporal dimension.

Since the support units of the ancillary variables and the target variables were more or less comparable in size, we did not deal with change of support. In other areas, where the support units of ancillary variables would be considerable greater, the issue of change of support in spatial prediction needs attention while applying the proposed methods.

\section{Conclusions}

(1) The developed GD mapping method is robust, costs less than a traditional GWT map, yields a complete set of parameters and is now routinely being applied.
(2) The uncertainty associated with mapping the MHW, MLW and MSW is mapped as well, which enables a motivated further investment in map improvement at known cost.

(3) The safest way, but at high cost, to improve map quality is to increase sampling density. Another option is to evaluate new sources of ancillary information, such as possibly may be derived from calculations with hydrological models.

\section{References}

Bierkens, M.F.P., Knotters, M., 1999. Calibration of transfer function-noise models to sparsely or irregularly observed time series. Water Resour. Res. 35, 1741-1750.

Braat, L.C., van Amstel, A.R., Gerritsen, A.C., van Gool, C.R., Gremmen, N., Groen, C.L.G., Rolf, H.L.M., Runhaar, J., Wiertz, J., 1989. Verdroging Van Natuur en Landschap in Nederland-Beschrijving en Analyse (Man-Induced Drought of Nature and Landscape in the Netherlands-Description and Analysis). Ministerie van Verkeer en Waterstaat, 's-Gravenhage. In Dutch.

Bregt, A.K., Stoorvogel, J.J., Bouma, J., Stein, A., 1992. Mapping ordinal data in a soil survey: a Costa Rican example. Soil Sci. Soc. Am. J. 56, 525-531.

Burgess, T.M., Webster, R., 1980. Optimal interpolation and isarithmic mapping of soil properties: I. The semi-variogram and punctual kriging. J. Soil Sci 31, 315-331.

Cohen, A.C., 1991. Truncated and Censored Samples: Theory and Applications. Dekker, New York.

Cressie, N.A.C., 1993. Statistics for Spatial Data, revised edition. Wiley, New York.

de Bakker, H., Schelling, J., 1986. A System of Soil Classification for The Netherlands. The Higher Levels. Soil Survey Institute, Wageningen in Dutch.

Deutsch, C.V., Journel, A.G., 1998. Gslib: Geostatistical Software Library and User's Guide, 2nd edition. Oxford Univ. Press, New York. Applied Geostatistics Series.

Finke, P.A., 2000. Updating the (1:50,000) Dutch groundwater table class map by statistical methods: an analysis of quality versus cost. Geoderma 97, 329-350.

Finke, P.A., Hoogland, T., Bierkens, M.F.P., Brus, D.J., de Vries, F., 1999. Pilot naar grondwaterkaarten in het Weerijsgebied (pilot study towards maps of groundwater dynamics in the Weerijs area). Alterra Proj. Rep., pp. 9-10 (in Dutch).

Gessler, P.E., Chadwick, O.A., Chamran, F., Althouse, L., Holmes, K., 2000. Modeling soil-landscape and ecosystem properties using terrain attributes. Soil Sci. Soc. Am. J. 64, 2046-2056.

Knotters, M., 2001. Regionalised time series models for water table depths. PhD thesis, Wageningen University.

Knotters, M., Bierkens, M.F.P., 2000. Physical basis of time series models for water table depths. Water Resour. Res. 36-1, 181-188. 
Mallows, C.L., 1966. Choosing a subset regression. Joint Statistical Meetings, Los Angeles, CA, 1996.

Massop, H.Th.L., Kroon, T., van Bakel, P.J.T., de Lange, W.J., van der Giessen, A., Pastoors, M.J.H., Huygen, J., 2000. Hydrologie voor STONE - schematisatie en parametrisatie (Hydrology for the STONE model - plot design and parameterisation). Alterra Rapport 038. Alterra-RIZA-RIVM, Wageningen. In Dutch.

te Riele, W.J.M., Brus, D.J., 1991. Methoden van gerichte grondwaterstandmetingen voor het schatten van de GHG (Methods to estimate MHW from phreatic head measurements). Rapport 158. DLO-Staring Centrum, Wageningen. In Dutch.
Thunnissen, H.A.M., Olthof, R., Gertz, P., Velts, L., 1992. Land cover database of the Netherlands based on Thematic Mapper images. Rapport 168. DLO Winand Staring Centre, Wageningen in Dutch.

van Bracht, M., 2001. Made to measure: information requirements and groundwater level monitoring networks. Thesis, Free University, Amsterdam and TNO NITG, Delft. 210 p.

Wösten, J.H.M., Bouma, J., Stoffelsen, G.H., 1985. Use of soil survey data for regional soil water simulation models. Soil Sci. Am. J. 49, 1238-1244. 